\title{
Cytological basis of the B chromosome accumulation mechanism in the grasshopper Heteracris littoralis (Ramb)
}

\author{
M. I. Cano and \\ J. L. Santos
}

\author{
Departamento de Genética, Facultad de Biología, \\ Universidad Complutense, 28040 Madrid, Spaỉn.
}

An accumulation mechanism of the standard B chromosome of the grasshopper Heteracris littoralis has been studied in a natural population located in EI Saler (Valencia) by two different methods: (i) the karyological analysis of the offspring from wild females and (ii) cytological observations of male and female meiosis. The transmission rate of the accessory through females obtained from crosses (0.61) was slightly lower than that obtained from direct meiotic observations of secondary oocytes $(0 \cdot 71)$. The $B$ chromosome is transmitted at a rate of about 0.5 through $1 B$ males, the value expected from mendelian segregation. The implications of these findings are discussed and the parasitic nature of the $B$ is proposed.

\section{INTRODUCTION}

One of the most striking features of B-chromosomes is their non-mendelian modes of inheritance that in many cases foster their accumulation rather than their elimination. There are two basic types of accumulation mechanisms. The first one operates by non-disjunction of the accessories in the gametophyte or at early meiosis of the germ line whereas in the second one Bs accumulate during meiosis in the egg (see Hewitt, 1979; Jones and Rees, 1982, for review). The transmission of Bs through the female side has usually been deduced from karyotyping studies of the progeny of single pair crosses in which the chromosome constitution of the parents was known. However there are two species where it has been demonstrated by direct cytological observations: Lilium callosum (Kayano, 1957) and Myrmeleotettix maculatus (Hewitt, 1976).

The knowledge of the transmission mechanisms of $\mathrm{B}$ chromosomes is especially relevant because it has been pointed out that they can explain the maintenance of $\mathrm{B}$ chromosome polymorphisms in natural populations. Those Bs that have accumulation mechanisms are considered "selfish" and their existence in natural populations would depend on a balance of their transmission rate with counter effects of reduced fertility or vigour for the individuals carrying them (Jones, 1985).

The present study was undertaken in order to determine whether the standard B chromosome of the grasshopper Heteracris littoralis (Cano and Santos, 1988) has an accumulation mechanism. For this purpose, we have compared in one natural population the transmission rate of this accessory obtained from cytological observations of male and female meiosis with that deduced from the analysis of the offspring of wild females which were inseminated by wild males.

\section{MATERIAL AND METHODS}

Adults, males $(2 n=23, \mathrm{XO})$ and females $(2 n=24$, $\mathrm{XX}$ ), were collected in El Saler (Valencia) during September, 1986. Twenty-five females were placed individually in small cardboard cages and were allowed to lay one egg pod each whereas the remainder (about 30) were kept in the laboratory in a standard locust cage in order to analyze their meiotic process. The insectary had a diurnal fluctuation in light, radiant heat, temperature and humidity generated by banks of electric light bulbs that were controlled by a time clock. The maximum and minimum temperatures were limited between $30^{\circ} \mathrm{C}$ and $20^{\circ} \mathrm{C}$. 
The embryos were dissected out of eggs kept for three weeks in moist sand in Petri dishes at $25^{\circ} \mathrm{C}$, immersed in 0.05 per cent colchicine in hypotonic insect saline for one hour and then fixed in $1: 3$ acetic alcohol. Subsequently they were squashed in 45 per cent acetic acid and stained by means of a C-banding method described previously (Santos and Giráldez, 1978). In the laying females the chromosomal constitution was determined from cells of the gastric caeca and follicular cells of the ovarioles. They were injected with a 0.2 per cent colchicine solution and were sacrificed four hours later. The gastric caeca and the ovaries were fixed and treated as the embryos. Testes of all the males studied were fixed in $1: 3$ acetic: alcohol without pretreatment.

Observations of female meiosis were made according to the method described by HenriquesGil et al. (1985).

\section{RESULTS}

\section{Transmission rate of the accessory obtained from crosses}

The results of the analysis of the 25 females and their offspring are summarized in table 1. For each mating the number of Bs carried by the male was inferred from the number of accessories in the female and her offspring. This method involves the assumption that a female is fertilized only by a single male and, although it is well known in grasshoppers that multiple matings occur in the laboratory and it is likely that they do under natural conditions, the assumption seems valid since it has been recently demonstrated in Eyprepocnemis plorans that even though a female has mated with several males each pod corresponds to the insemination of a single male. In fact, several pods may belong to the same insemination (López, 1987). Similar matings were grouped together.

A respectable number of progeny were obtained for the $1 \mathrm{~B} 0 \mathrm{~B}$ crosses but because of the

Table 1 A summary of the 25 matings and the number of their offspring with various numbers of $\mathrm{Bs}$

\begin{tabular}{|c|c|c|c|c|c|c|c|c|}
\hline \multicolumn{2}{|l|}{ Mating } & \multirow{2}{*}{$\begin{array}{l}\text { Number } \\
\text { of } \\
\text { crosses }\end{array}$} & \multicolumn{5}{|c|}{ Offispring } & \multirow[b]{2}{*}{$x^{2}$} \\
\hline Female & Male & & $O B$ & $1 B$ & $2 \mathrm{~B}$ & $3 \mathrm{~B}$ & $\mathrm{~T}$ & \\
\hline$O B$ & $\mathrm{OB}$ & 14 & 140 & - & - & - & 140 & - \\
\hline $0 B$ & $1 \mathrm{~B}$ & 5 & 93 & 101 & - & - & 194 & $0 \cdot 33$ \\
\hline $1 \mathrm{~B}$ & $0 \mathrm{~B}$ & 5 & 86 & 134 & - & - & 220 & $10 \cdot 47^{*}$ \\
\hline $2 B$ & $1 \mathrm{~B}$ & 1 & 1 & 27 & 25 & 1 & 54 & - \\
\hline
\end{tabular}

* Significant at five per cent level. low frequency of $2 \mathrm{~B}$ individuals in this population (Cano and Santos, 1988) we have only found a cross in which one individual with two accessories is involved. The transmission of the $B$ through the male side fits to mendelian expectations. However, there is a clear accumulation of Bs when transmitted through the female side $(0.61$ instead of the expected $0 \cdot 5)$. The offspring obtained in the cross 2B 1B can be explained on the assumption of a high pairing frequency of Bs in the female. In all cases the ratio of males to females among the embryos was $1: 1$.

The $0 \mathrm{~B}$ females laid an average of 37.83 eggs per pod, while 1B females laid 35.57 eggs per pod. The difference is not statistically significant $(t=$ $0 \cdot 502, \mathrm{df}=15$ ).

\section{Meiotic behaviour of the $B$}

The B chromosome is mitotically stable. In, the testis it is positively heteropycnotic during the first meiotic prophase and in many cells it is associated with the $X$ chromosome that also shows a similar heteropycnotic condition. These associations disappear at metaphase I and both chromosomes lie outside the equatorial plate (fig. 1). The B chromosome usually divides in a reductional way at anaphase I (fig. 3) with chromatid separation at anaphase II. The transmission rate of this chromosome by male side can be considered close to 0.5 (Cano and Santos, 1988).

Only eight of the 30 females used for meiotic analysis possessed one $B$ chromosome. The accessory always lies outside the equatorial plate at metaphase I (fig. 2) and goes undivided to one pole at anaphase I (fig. 4). At late anaphase I one of the poles appears regularly more condensed than the other. However, our observations do not allow us to ascertain the polar body and the egg side. For this reason, we have analyzed metaphase and anaphase II cells (figs 5 and 6; table 2). Only one cell among the 70 analyzed at this stage showed one $B$ chromatid which indicates that the reductional division of $\mathrm{B}$ at anaphase $\mathrm{I}$ can be considered as a general rule; 50 showed $1 \mathrm{~B}$ chromosome and $190 \mathrm{~B}$ thus the transmission rate of the accessory

Table 2 The distribution of B chromosomes in secondary oocytes of $1 \mathrm{~B}$ females of Heteracris littoralis

\begin{tabular}{llllll}
\hline $\begin{array}{l}\text { No. of } \\
\text { females } \\
\text { with 1B }\end{array}$ & \multicolumn{3}{l}{ MII and AII cells } & \\
\cline { 2 - 5 } & $0 \mathrm{~B}$ & $1 \mathrm{~B}$ & $1 \mathrm{~B}$ crt & $T$ & $\chi^{2}$ \\
\hline 8 & 19 & 50 & 1 & 70 & $13.92^{*}$ \\
\hline
\end{tabular}

* Significant at five per cent level. 

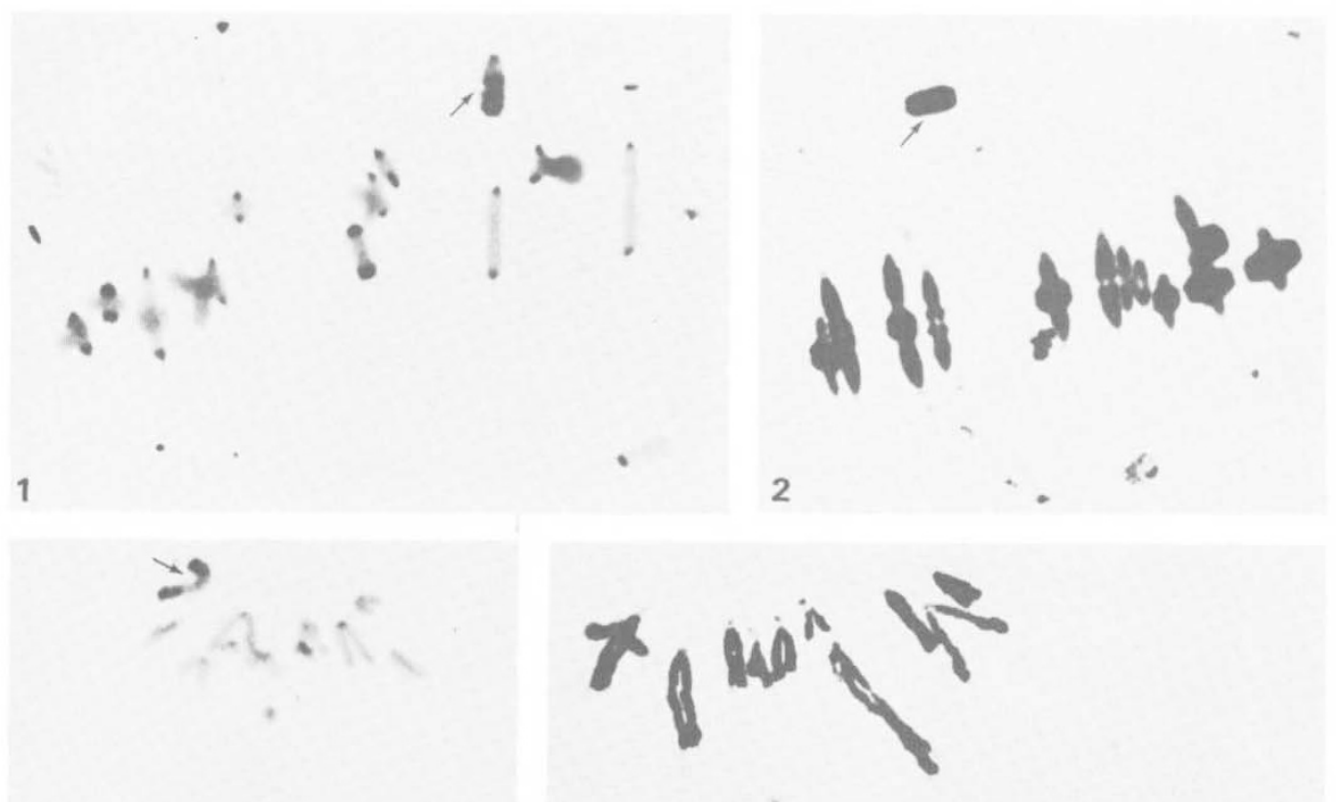

3

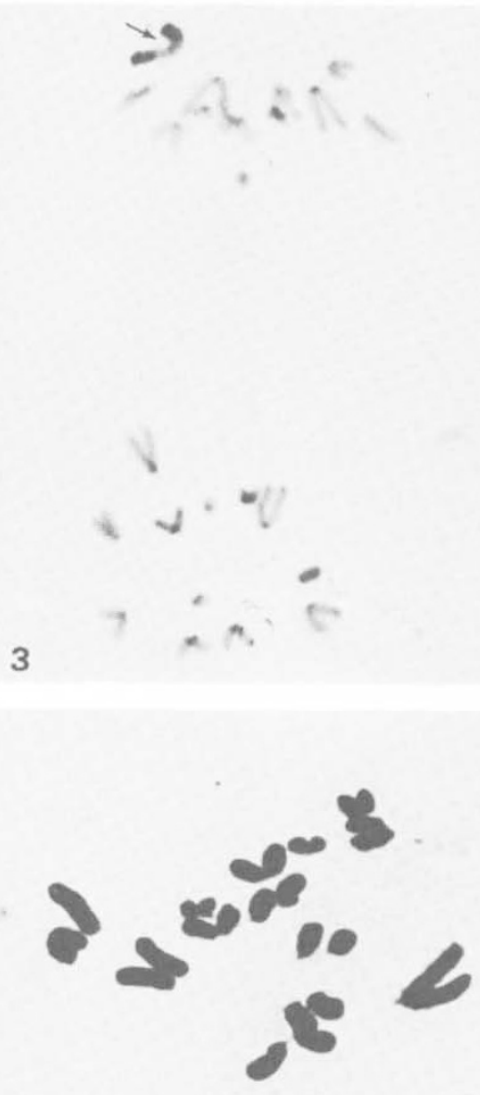

5
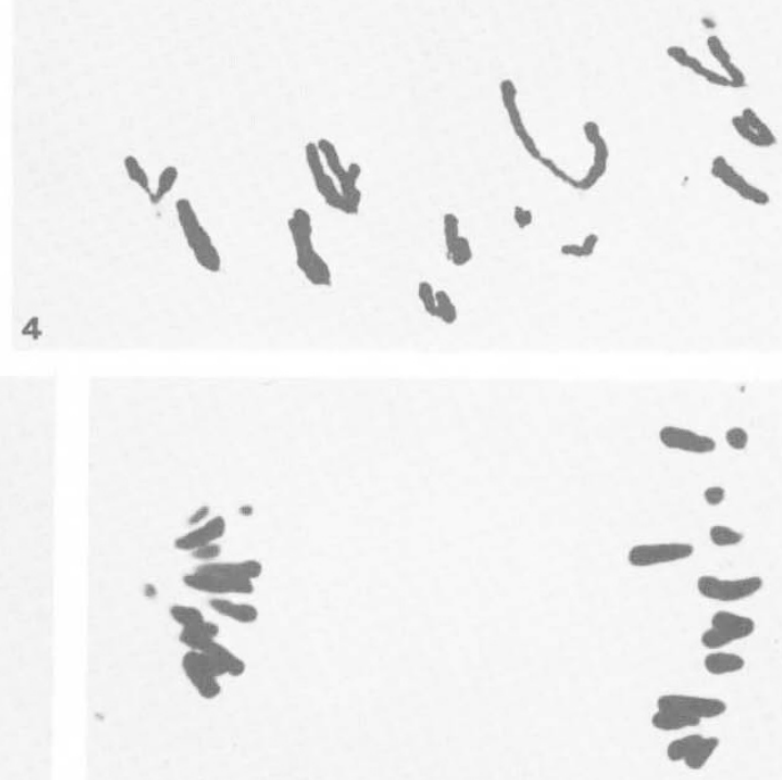

6

Figure 1. C-banded metaphase I cell from a 1B male. Figure 2. Metaphase I cell from a 1B female. Figure 3. C-banded anaphase I cell from a 1B male. Figure 4. Anaphase I cell from a 1B female with 12 chromosomes in one pole and 13 in the other. Figure 5. Metaphase II cell from a $1 \mathrm{~B}$ female containing 13 chromosomes. The accessory is included. Figure 6. Anaphase II cell from a $1 \mathrm{~B}$ female with 13 chromatids in each pole.

Arrows indicate B chromosomes in those cells in which they were undoubtedly identified. 
calculated from cytological observations of female meiosis is about 0.71 .

Summarising, the B standard of $H$. littoralis shows an accumulation mechanism based on a preferential orientation of B on the egg side at anaphase $\mathrm{I}$. The transmission rate obtained from crosses $\left(k^{\prime}=0 \cdot 61\right)$ however is slightly lower than that obtained from direct cytological observations of female meiosis $(k=0 \cdot 71)$.

\section{DISCUSSION}

One of the two mechanisms of accumulation of accessory chromosomes is the preferential segregation of univalent Bs at meiosis. This mechanism has usually be inferred from breeding experiments either in animals (Lucov and Nur, 1973; Nur, 1977; Gregg et al., 1984; Thomson, 1984) or plants (Vosa, 1962; Subba Rao, 1980; Parker et al., 1982). However, up to date, there are only two cases in which this has been demonstrated at cytological level: M. maculatus (Hewitt, 1976) and L. callosum (Kayano, 1957). In the former species the spindle in the primary oocyte is asymmetric and univalent B chromosomes are distributed preferentially to the longer conical (egg) side rather than to the shorter conical (polar body) side whereas in the latter species there is no asymmetry of the spindle, although the egg mother cell itself is often placed nearer to the micropylar than to the chalazal end of the embryo sac.

The results shown in tables 1 and 2 clearly demonstrate that the standard B chromosome of the grasshopper $H$. littoralis is included in the secondary oocyte at an increased frequency over mendelian expectations. In most of the cases neither the cellular shape of the primary oocytes nor the position of the equatorial plate with respect to the attraction poles could be distinguished. However, we have observed that in late anaphase I cells one of the poles is more condensed than the other which may be a reflection of an asymmetrical spindle. Thus, the explanation for meiotic drive proposed by Hewitt (1976) and based on the conical shape of the nucleoplasm surrounding the spindle may also be adequate for this species.

In those species in which the $\mathrm{B}$ is transmitted by the female at a rate higher than $0 \cdot 5$, namely Melanoplus femur-rubrum (Lucov and Nur, 1973; Nur, 1977), Chortoicetes terminifera (Gregg et al, 1984), M. maculatus (Hewitt, 1976) and L. callosum (Kayano, 1957), the transmission rate was about $0 \cdot 7-0 \cdot 8$. In the two latter species there is a close agreement between the frequency of the $B$ chromosome orientation to the egg cell and the level of preferential transmission in crosses. This does not seem to be the case in $H$. littoralis where there is a slight difference between the transmission rates obtained by the two different methods employed here: the B chromosome appears in the secondary oocyte in 71 per cent cells whereas it is transmitted to the offspring with a rate of 0.61 . Although this difference is not statistically significant, the possibility of a selective pressure against gametes or zygotes carrying a B chromosome may not be excluded and further studies based on cytological observations of meiosis in both members of specific pairwise crosses and karyoptical analysis of their offspring will be necessary to test this hypothesis.

Table 3 Frequencies of the standard B chromosome of Heteracris littoralis in El Saler population during two consecutive years

\begin{tabular}{|c|c|c|c|c|c|c|}
\hline \multirow[b]{2}{*}{ Year } & \multicolumn{4}{|c|}{ Individuals with } & \multirow{2}{*}{$\begin{array}{l}\text { Bs } \\
\text { ind. }\end{array}$} & \multirow[b]{2}{*}{$x^{2}$} \\
\hline & $\mathrm{OB}$ & 1B & $2 \mathrm{~B}$ & $\mathrm{~T}$ & & \\
\hline 1985 males & 27 & 12 & - & 39 & $0 \cdot 31)$ & 0.3 \\
\hline $\begin{array}{l}1986 \text { (males) } \\
\text { and females) }\end{array}$ & 51 & 16 & 2 & 69 & 0.29 & n.s. \\
\hline
\end{tabular}

In species in which accumulation mechanisms for B chromosomes have been described it is assumed that the accessories must reduce the fitness of the individuals carrying them (for references see Jones and Rees, 1982). In $H$. littoralis Bs do not seem to affect female fecundity because the number of eggs per pod is similar in females with $0 \mathrm{~B}$ and $1 \mathrm{~B}$. As has been mentioned above $\mathrm{Bs}$ can produce a reduction of fitness in the individuals carrying them manifested at the gametic stage and perhaps other stages too. The observed rates of transmission of $k^{\prime}=0.61$ in the female and $k=0.5$ in the male are expected to lead to a ten per cent increase in the frequency of the $B$ every generation and the frequency of accessories in El Saler population has not apparently changed in the past two years (see table 3 ). A tentative conclusions is that the standard B chromosome of $H$. littoralis can be maintained in natural populations simply on the basis of the accumulation mechanism and hence it can be considered to be of a parasitic nature.

Acknowledgement This work was supported by a grant of Universidad Complutense (UCP01687). 


\section{REFERENCES}

CANO, M. I. AND SANTOS, J. L. 1988. B chromosomes of the grasshopper Heteracris littoralis: meiotic behaviour and endophenotypic effects in both sexes. Genome, (in press).

GREGG, P. C., WEBB, G. C. AND ADENA, M. A. 1984. The dynamics of B chromosomes in populations of the Australian plague locust Chortoicetes terminifera (Walker). Can. J. Genet. Cytol., 26, 194-208.

HENRIQUES-GIL, N., JONES, G. H., CANO, M. I., ARANA, P. AND SANTOS, I. L. 1985. Female meiosis during oocyte maturation in Eyprepocnemis plorans (Orthoptera: Acrididae). Can. J. Genet. Cytol., 28, 81-87.

HEWITT, G. M. 1986. Meiotic drive for B-chromosomes in the primary oocytes of Myrmeleotettix maculatus (Orthoptera: Acrididae). Chromosoma, 56, 381-391.

HEWITT, G. M. 1979. Animal cytogenetics, 3. Insecta, 1. Orthoptera. Gebr Borntrager, Berlin-Stuttgart.

JONES, R. N. 1985. Are B chromosomes selfish? In CavalierSmith, T. (ed.) The Evolution of Genome Size, Chapter 13, $397-425$

JONES, R. N. AND REES, H. 1982. B-chromosomes. Academic Press, New York.

KAYANO, H. 1957. Cytogenetic studies in Lilium callosum. III. Preferential segregation of a supernumerary chromosome in EMC's. Proc. Jap. Acad., 33, 553-558.
LOPEZ LEON, M. D. 1987. Estudio de la transmisión de dos tipos de heterocromatina extra en dos especies de saltamontes. Tesina de licenciatura. Univ. de Granada.

LUCOV, Z. AND NUR, U. 1973. Accumulation of B-chromosomes by preferential segregation in females of the grasshopper Melanoplus femur-rubrum. Chromosoma, 42, 289-306.

NUR, U. 1977. Maintenance of a "parasitic" B chromosome in the grasshopper Melanoplus femur-rubrum. Genetics, 87, 499-512

PARKER, J. S., 'TAYLOR, S. AND AINSWORTH, C. C. 1982. The B chromosome system of Hypochoeris maculata. III. Variation in B-chromosome transmission rates. Chromosoma, 85, 299-310.

SANTOS, J. L. AND GIRALDEZ, R. 1978. The effect of C-heterochromatin in chiasma terminalization in Chorthippus biguttulus L. (Acrididae, Orthoptera), Chromosoma, 70. 59-66.

SUBBA RAO, R. W. 1980. Inheritance of B-chromosomes in pearl millet. Heredity, 45, 1-6.

THOMSON, R. L. 1984. B chromosomes in Rattus fuscipes II. The transmission of B chromosomes to offspring and population studies support for the "parasitic" model. Heredity, $52,363-372$.

VOSA, C. G. 1962. The transmission of B chromosomes in Tradescantia virginiana. Chromosome Inform. Serv., 3, 26-28. 